\title{
Chemical and Metabolic Properties of Various Elements Found in Cultures of a Stable Proteus L Form
}

\author{
By C. WEIBULL AND H. BECKMAN \\ Central Bacteriological Laboratory of Stockholm City, Stockholm, Sweden
}

(Received 20 September 1960)

\begin{abstract}
SUMMARY
The microscopic elements which constituted cultures of a stable $L$ form (Proteus L9) were found to be highly heterogeneous with respect to morphological, chemical and metabolic properties. The smallest elements found in the cultures studied (diameter $<0.3 \mu$ ) contained more lipid-phosphorus (lipid-P), but less ribonucleic acid-phosphorus, deoxyribonucleic acid-phosphorus and protein-nitrogen, than whole cultures consisting predominantly of bodies of diameter $>1 \mu$. The small elements respired at about the same rate as whole cultures, but they showed low, if any, biosynthetic activity. The small elements probably possess a structural organization similar to that of $\mathrm{L}$ bodies of larger sizes, but most of them contained little, if any DNA.
\end{abstract}

\section{INTRODUCTION}

The bacterial L forms (reviewed by Dienes \& Weinberger, 1951; Tulasne, 1955; Kandler \& Kandler, 1960; Kleineberger-Nobel, 1960) are highly pleomorphic. Vesicular and granular elements are most frequent in cultures of $\mathbf{L}$ forms, but various irregular structures may also be found. Mandel and his associates have published a series of papers describing the fractionation of $\mathrm{L}$ cultures into fractions characterized among other things by the size of the elements present in them (Mandel, Terranova \& Sensenbrenner, 1957; Mandel, Feo, Sensenbrenner \& Terranova, 1959; Mandel, Terranova, Sensenbrenner \& Feo, 1959; Mandel et al. 1959). The fractionation was performed by means of differential centrifugation. This technique has been used in most of the experiments described in the present paper. A stable L form derived from Proteus mirabilis was investigated.

\section{METHODS}

Organism. The Proteus L form used was obtained from Dr E. KlienebergerNobel (Lister Institute of Preventive Medicine, London). It has not shown any signs of reversion during its history and has been designated as strain L 9 (Klieneberger-Nobel, 1956). Tests performed in our laboratory have shown that the normal Proteus strain from which Proteus L9 was derived does not produce acid and gas from maltose, and does not produce indole; this strain thus exhibits the properties of Proteus mirabilis (see Taubeneck, 1956).

Growth conditions and harvesting of the cultures. Samples of the $\mathrm{L}$ form were obtained for experimental purposes from stock cultures grown in $250 \mathrm{ml}$. Erlenmeyer flasks containing $50 \mathrm{ml}$. of the liquid serum-free medium described by 
Abrams (1955). No penicillin, however, was included in the medium used in the present work. The culture were incubated for $24 \mathrm{hr}$. at $30^{\circ}$ on a rotary shaker (100 rev./min.) and stored at room temperature. Subcultures were made every week.

To obtain large amounts of $\mathrm{L}$ form grown in a liquid medium, 3 l. Erlenmeyer flasks containing $500 \mathrm{ml}$. medium were used. The flasks were inoculated with $50 \mathrm{ml}$. of an overnight culture of Proteus L9, obtained as described above.

For the growth of Proteus L9 on solid medium, Petri dishes (diam. $20 \mathrm{~cm}$.) were used containing Abram's liquid medium supplemented with $0 \cdot 8 \%(\mathrm{w} / \mathrm{v})$ Difco agar. The plates were heavily inoculated with a liquid culture of Proteus L9 and incubated for $48 \mathrm{hr}$. at $30^{\circ}$. For harvesting the $\mathrm{L}$ bodies, a liquid culture of Proteus L9 was centrifuged for $20 \mathrm{~min}$. at $78,000 \mathrm{~g}$. The supernatant fluid was used for suspending the growth present on the Petri plates.

Differential centrifugation. The centrifugations were made with a Spinco model $\mathrm{L}$ preparative ultracentrifuge equipped with a no. 30 rotor (tube diameter $2.54 \mathrm{~cm}$., tubes inclined $26^{\circ}$ from axis of rotation). In each fractionation experiment the centrifugations were conducted in two centrifugal fields, as outlined in Fig. 1. All centrifugations lasted for 20 min., plus the time required for stopping the rotor with the magnetic brake.

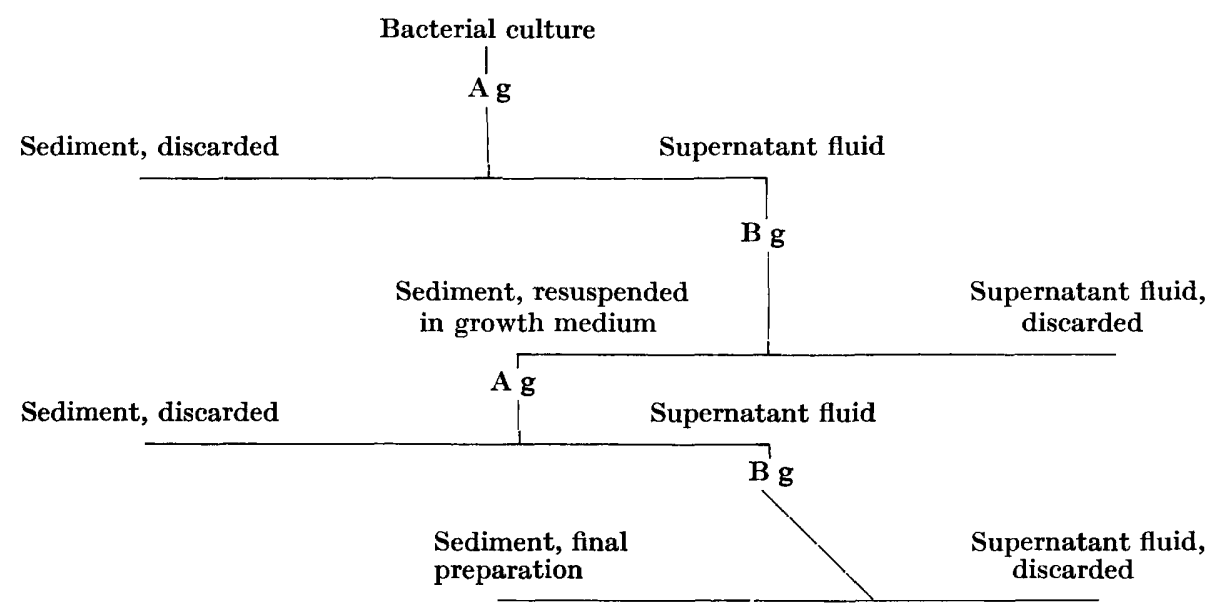

Fig. 1. Fractionation of $L$ elements by means of differential centrifugation. The symbols ' $\mathrm{A} \mathrm{g}$ ' and $\mathrm{B}$ g' stand for the centrifugal fields used.

Chemical analyses. For the determination of lipid-phosphorus, nucleic acids and protein, samples were subjected to the Schneider fractionation procedure (Schneider, 1945; Weibull \& Beckman, 1960). Total phosphorus in the lipid fraction (lipid-P) was determined according to Allen (1940). Ribonucleic acid-phosphorus (RNA-P) was determined as described by Schneider (1945) and deoxyribonucleic acid-phosphorus (DNA-P) according to Burton (1956). The Kjeldahl method was used to estimate protein nitrogen (protein-N). The dry weight of bacterial material was determined as described by Weibull \& Beckman (1960).

Enzyme assays and measurements of respiration. Succinic dehydrogenase was determined according to Storck \& Wachsman (1957). Catalase was estimated by 
the method described by Bonnichsen, Chance \& Theorell (1947). These measurements were made at room temperature. The conventional Warburg technique was used for respiration measurements. The experiments were conducted at $30^{\circ}$.

Isotope experiments. ${ }^{32} \mathrm{P}$ was obtained from the Radiochemical Centre, Amersham, Buckinghamshire, England. Activities were measured with a Tracerlab TGC-2 Geiger tube, connected to a Tracerlab SC33A '1000' Scaler. Samples were measured either wet (volume of sample $1 \mathrm{ml}$.) or after drying at $100^{\circ}$.

\section{RESULTS}

\section{Fractionation by means of filtration}

The experiments described in this section were performed with Proteus L9 grown in Abram's liquid medium. Microscopical inspection revealed spherical bodies of various sizes as predominant constituents of these cultures (see Weibull \& Beckman, 1960); minor amounts of morphologically ill-defined material were also seen. The spherical bodies were single, or formed small aggregates, each consisting usually of less than 10 individual spheres. When the $\mathbf{L}$ cultures were centrifuged at high speed in the Spinco centrifuge, a sediment consisting of two rather welldefined layers was usually formed. The upper one was transparent, the lower one opaque. However, when the two layers were resuspended separately in the growth medium, the suspensions obtained could not be clearly distinguished from each other when viewed by phase-contrast microscope.

Up to about half of the bacterial material of a Proteus L9 culture did not pass through a Munktell 1 F filter paper (manufactured by Grycksbo Pappersbruk, Ltd, Grycksbo, Sweden). When the filtrate was centrifuged, the opaque material mentioned above was almost completely absent from the centrifugal pellet. The filtered bacterial material always contained more lipid-P and nucleic acid phosphorus per mg. dry weight than the corresponding unfiltered material. On the other hand, the content of protein- $\mathrm{N}$ was about the same in the two kinds of material. Thus the ratio content of lipid-P, RNA-P, DNA-P, protein-N, in 1 g. dry wt. filtered material to content of same substance in $1 \mathrm{~g}$. unfiltered material was found to be: lipid-P, 1.36; RNA-P, 1.36; DNA-P, 1.41; protein-N, 0.94. These figures represent average values obtained from four separate experiments.

The respiration of filtered $\mathrm{L}$ cultures was found to be about $30 \%$ more vigorous than that of unfiltered material, calculated per mg. bacterial dry weight.

\section{Fractionation by means of differential centrifugation}

The main purpose of these experiments was to isolate from $\mathrm{L}$ cultures small elements similar to those described by Tulasne (1955) and to study the chemical and metabolic properties of these elements as compared with those of the unfractionated cultures. Cultures grown in a liquid medium and on a solid medium (see Methods) were investigated. The type of medium did not influence the results markedly. However, larger yields of bacterial material were obtained when Proteus L9 was grown on a solid medium. When not otherwise mentioned, the data reported below refer to experiments carried out with solid medium.

Morphological studies. As with L cultures grown in liquid medium, unfractionated cultures grown on solid medium consisted essentially of spherical elements 
of various sizes. Electron microscopical observations showed that the fractions obtained by differential centrifugation contained essentially elements having a diameter $<\mathbf{0 \cdot 3} \mu$.

Chemical studies. Unfractionated and fractionated $\mathbf{L}$ cultures were analysed for lipid-P, protein-N, RNA-P and DNA-P. Table 1 gives data from a number of independent experiments. The gravitational fields applied for fractionation of the $\mathrm{L}$ cultures differed from experiment to experiment, ranging from 5500 to $78,000 \mathrm{~g}$. The fractions were examined by oil-immersion phase-contrast microscopy; this revealed granular elements of a size near the resolving limit of the microscope as predominant elements in all the fractions obtained.

The figures collected in Table 1 show that, on a dry-weight basis, the unfractionated $\mathrm{L}$ bodies contained on an average more RNA-P, DNA-P and protein-N than the small elements isolated from them, but less lipid-P. The wide variations in the DNA-P content of the small bodies should be emphasized; the maximal and minimal values differed by a factor of 64 . The corresponding factor for the other compounds assayed varied between $1 \cdot 2$ and $4 \cdot 8$.

\section{Table 1. Chemical composition of unfractionated $L$ cultures and of fractions of such cultures obtained by differential centrifugation at 5500-78,000 $\mathrm{g}$}

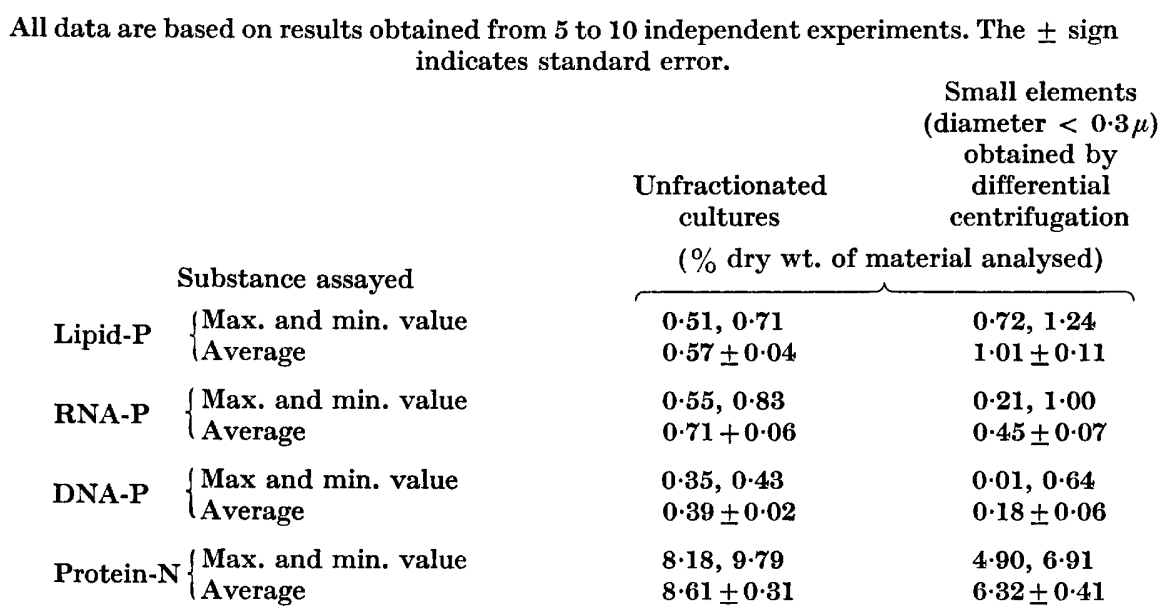

The pronounced fluctuations in the DNA content of the fractionated L cultures suggest that at least part of the DNA did not form an integral part of the spherical bodies in these preparations. To test this hypothesis crystalline DNAse (Mann Research Laboratories Inc., New York 6, N.Y., U.S.A.) was added to a suspension of small $\mathrm{L}$ elements in the growth medium. The mixture was incubated for $2 \mathrm{hr}$. at $30^{\circ}$ and then analysed for lipid-P, RNA-P and DNA-P; an unfractionated culture containing mainly elements having a diameter $>1 \mu$ was similarly treated. This culture had been grown in liquid medium, since $\mathbf{L}$ bodies grown on solid medium have a tendency to lyse when suspended in a fluid and then probably release DNA.

Table 2 shows the results of the digestion experiment. It can be seen that the chemical composition of the unfractionated culture was not influenced by the 
enzymic treatment. The content of lipid-P and RNA-P in the 'small elements remained practically constant during the treatment with DNAse. The DNA-P content, on the other hand, diminished by about $70 \%$.

Table 2. Digestion with DNAse of a n unfractionated $L$ culture and of a fraction of such a culture obtained by means of differential centrifugation

The fractionated preparation contained only small elements (diameter $<\mathbf{0 \cdot 3 \mu}$ ); the unfractionated culture mainly elements of diameter $>1 \mu$. The digestion took place in the growth medium at $30^{\circ}$ for $2 \mathrm{hr}$. The concentration of DNAse was $0.5 \mathrm{mg} . / \mathrm{ml}$., that of the $\mathrm{L}$ elements about $1 \mathrm{mg}$. dry wt./ml.

\begin{tabular}{|c|c|c|c|c|}
\hline \multirow{3}{*}{ Substance assayed } & \multicolumn{2}{|c|}{ Unfractionated $\mathbf{L}$ culture } & \multicolumn{2}{|c|}{$\begin{array}{l}\text { Fraction containing } \\
\text { small L elements }\end{array}$} \\
\hline & $\begin{array}{c}\text { Before } \\
\text { digestion }\end{array}$ & $\begin{array}{c}\text { After } \\
\text { digestion }\end{array}$ & $\begin{array}{c}\text { Before } \\
\text { digestion }\end{array}$ & $\begin{array}{c}\text { After } \\
\text { digestion }\end{array}$ \\
\hline & \multicolumn{4}{|c|}{$\%$ dry wt. material analysed } \\
\hline Lipid-P & $0 \cdot 60$ & 0.60 & $1 \cdot 15$ & $1 \cdot 14$ \\
\hline RNA-P & $0 \cdot 68$ & $0 \cdot 69$ & $0 \cdot 41$ & 0.42 \\
\hline DNA-P & $0 \cdot 36$ & $\mathbf{0} \cdot \mathbf{3 6}$ & $0 \cdot 28$ & 0.09 \\
\hline
\end{tabular}

As mentioned in Table 1 the data about small $\mathrm{L}$ elements refer to batches obtained by centrifugation at different centrifugal fields. To test the relationship between the centrifugal fields applied and the chemical composition of the fractions obtained, some $L$ cultures were fractionated into two or three fractions. Each fraction was isolated as outlined in Fig. 1 and was analysed chemically. Table 3 shows the results of three experiments of this kind. It can be seen that the RNA-P content of elements collected by using high centrifugal fields tended to be lower than that of elements obtained by centrifugation at lower speeds. The content of DNA-P, lipid-P and protein-N in the fractions analysed varied less, or in an irregular manner.

Table 3. Chemical composition of $L$ elements isolated by means of differential centrifugation at various centrifugal fields

The centrifugations were carried out as outlined in Fig. 1.

\begin{tabular}{|c|c|c|c|c|c|}
\hline \multirow[b]{2}{*}{ Expt. } & \multirow{2}{*}{$\begin{array}{l}\text { Applied centrifugal } \\
\text { fields }(g)\end{array}$} & Lipid-P & RNA-P & DNA-P & Protein $\mathrm{N}$ \\
\hline & & \multicolumn{4}{|c|}{ ( $\%$ dry weight of the bacterial material analysed) } \\
\hline \multirow[t]{3}{*}{ I } & $2,100,5,500$ & - & 0.54 & 0.016 & - \\
\hline & $5,500,19,600$ & 一 & 0.43 & 0.020 & - \\
\hline & $19,600,78,000$ & - & $0 \cdot 21$ & 0.008 & - \\
\hline \multirow[t]{2}{*}{ II } & $2,100,5,500$ & - & 0.39 & 0.068 & - \\
\hline & $5,500,19,600$ & - & 0.28 & 0.038 & - \\
\hline \multirow[t]{2}{*}{ III } & $2,100,5,500$ & $0 \cdot 65$ & 0.50 & $0 \cdot 17$ & 6.91 \\
\hline & $5,500,19,600$ & $0 \cdot 80$ & 0.51 & 0.20 & $6 \cdot 68$ \\
\hline
\end{tabular}

To compare the structural and macromolecular organization of $\mathrm{L}$ bodies of various sizes, unfractionated and fractionated $\mathrm{L}$ cultures were shaken in a Mickle disintegrator (Mickle, 1948) for $2 \mathrm{~min}$. After this treatment only bodies or fragments of a size near the resolving power of the light microscope were seen in the cultures. The broken material was centrifuged at $103,000 \mathrm{~g}$ for $20 \mathrm{~min}$. The supernatant liquid 
obtained was centrifuged for a further $120 \mathrm{~min}$. at $103,000 \mathrm{~g}$, transferred to fresh tubes and again centrifuged at the same speed for a further $120 \mathrm{~min}$. Table 4 shows the distribution of lipid-P, RNA-P and DNA-P in the fractions obtained by this centrifugation procedure. It can be seen that the greater part of the lipid-P of both whole $\mathrm{L}$ cultures (mainly containing bodies with a diameter $>1 \mu$ ) and small $\mathrm{L}$ bodies (diameter $<\mathbf{0} \cdot \mathbf{3} \mu$ ) was sedimented when the disintegrated $\mathrm{L}$ bodies were centrifuged at $103,000 \mathrm{~g}$ for $20 \mathrm{~min}$. Most of the DNA-P was sedimented after prolonged centrifugation at the same speed. The RNA-P of the whole $\mathrm{L}$ cultures and the small $\mathrm{L}$ bodies behaved differently when the disintegrated cultures were centrifuged. Thus about $80 \%$ of the RNA-P of the small L bodies was sedimented after centrifugation at $103,000 \mathrm{~g}$ for $20 \mathrm{~min}$., whereas about half of the RNA-P of unfractionated cultures was not sedimented even after centrifugation at the same speed for $260 \mathrm{~min}$.

Table 4. Distribution of lipid-P, RNA-P and DNA-P in fractions of $L$ bodies obtained by disruption of these bodies in a Mickle disintegrator and differential centrifugation of the disintegrated material

Each figure represents an average value from two independent experiments.

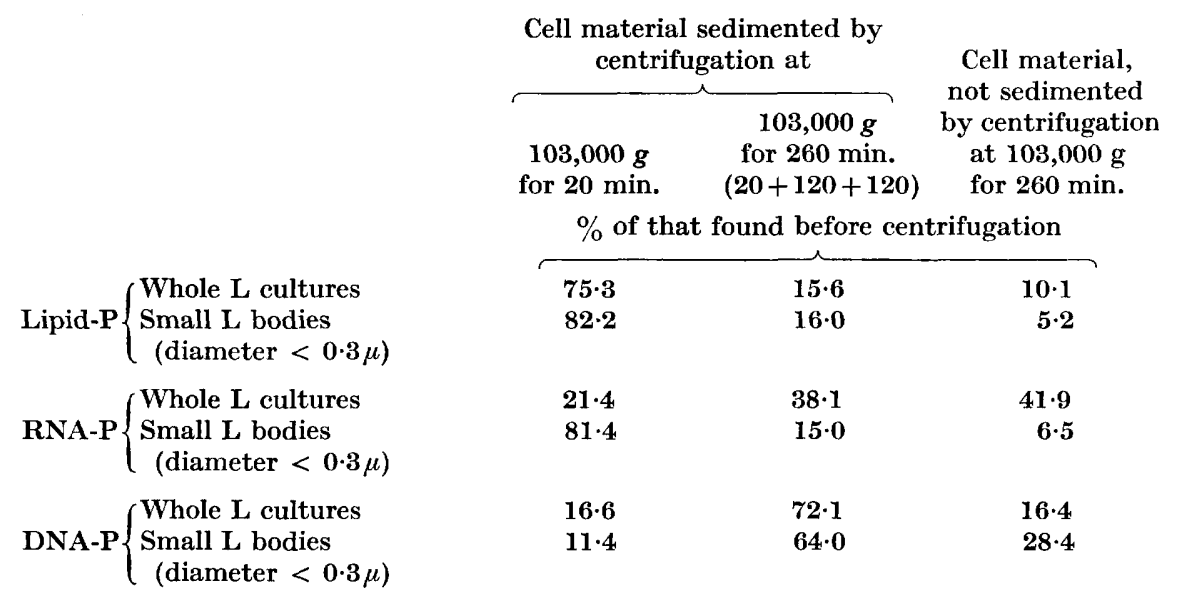

Enzyme studies. Many enzymes of the bacterial cell are undoubtedly located in definite subcellular structures (Marr, 1960). To elucidate the nature of the small bodies (diameter $<0.3 \mu$ ) isolated from whole $\mathbf{L}$ cultures by means of differential centrifugation, some enzymic activities of these bodies were studied and compared with those of unfractionated cultures. Succinic dehydrogenase and catalase were the two enzymes chosen for this investigation since they are located differently, at least in some bacteria (Alexander \& Wilson, 1955; Weibull, Beckman \& Bergström, 1959). The amounts of succinic dehydrogenase and catalase found in unfractionated cultures of Proteus L9 grown on a solid medium, and of fractions of such cultures obtained by means of differential centrifugation were: succinic dehydrogenase, $20 \cdot 8 \pm 1 \cdot 6$ and $35 \cdot 0 \pm 2 \cdot 1$ units; catalase $70,000 \pm 3200$ and $20,100 \pm 2600$ units (the enzymic activities are expressed as $\mu$ mole of substrate oxidized or split per min. and per 1 . of an incubation mixture containing $1 \mathrm{~g}$. dry weight bacterial material). 
Thus the unfractionated $\mathrm{L}$ bodies contained more catalase but less succinic dehydrogenase than the fractionated material.

The localization of succinic dehydrogenase and catalase in $\mathrm{L}$ bodies of various sizes was investigated by treating unfractionated and fractionated $\mathbf{L}$ cultures in a Mickle disintegrator and centrifuging the broken material in the manner used for characterization of the macromolecular organization of the $\mathbf{L}$ bodies by means of chemical analyses (see the preceding section of this paper); Table 5 shows the results of these experiments. It can be seen that both the catalase and the succinic dehydrogenase of the $\mathrm{L}$ bodies were distributed in much the same manner in unfractionated L cultures (containing mainly elements having a diameter $>1 \mu$ ) and in small $\mathrm{L}$ bodies (diameter $<\mathbf{0 \cdot 3} \mu$ ). The succinic dehydrogenase was associated with sedimentable matter, whereas the major part of the catalase was not sedimented even after prolonged centrifugation at high gravitational fields.

Table 5. Distribution of succinic dehydrogenase and catalase in fractions of $L$ bodies obtained by disruption of these bodies in a Mickle disintegrator and differential centrifugation of the disintegrated material

The results are expressed as per cent of total enzymic activity of the material before the centrifugation procedure

\begin{tabular}{|c|c|c|c|c|}
\hline & & \multicolumn{2}{|c|}{$\begin{array}{l}\text { Cell material sedimented by } \\
\text { centrifugation at }\end{array}$} & \multirow{2}{*}{$\begin{array}{l}\text { Cell material not } \\
\text { sedimented by } \\
\text { centrifugation } \\
\text { at } 103,000 \mathrm{~g} \\
\text { for } 260 \mathrm{~min} \text {. }\end{array}$} \\
\hline & & $\begin{array}{l}103,000 \mathrm{~g} \\
\text { for } 20 \mathrm{~min} .\end{array}$ & $\begin{array}{c}103,000 \mathrm{~g} \\
\text { for } 260 \mathrm{~min} . \\
(20+120+120)\end{array}$ & \\
\hline Succinic dehydrogenase & $\left\{\begin{array}{c}\text { Whole cultures } \\
\text { Small } \mathbf{L} \text { bodies } \\
(\text { diameter } \\
<0 \cdot 3 \mu)\end{array}\right.$ & $\begin{array}{l}72 \cdot 1 \\
69 \cdot 0\end{array}$ & $\begin{array}{l}<1 \\
<1\end{array}$ & $\begin{array}{l}<1 \\
<1\end{array}$ \\
\hline Catalase $\left\{\begin{array}{c}\text { Whole } \mathbf{L} \text { cultu } \\
\text { Small } \mathbf{L} \text { bodie } \\
<0.3 \mu)\end{array}\right.$ & $\left\{\begin{array}{l}\text { Small L bodies (diameter } \\
<0 \cdot 3 \mu)\end{array}\right.$ & $\begin{array}{l}1 \cdot 0 \\
5 \cdot 0\end{array}$ & $\begin{array}{l}30 \cdot 4 \\
29 \cdot 6\end{array}$ & $\begin{array}{l}52 \cdot 0 \\
48 \cdot 0\end{array}$ \\
\hline
\end{tabular}

Respiration experiments. Measurements were carried out on unfractionated $\mathbf{L}$ cultures grown in liquid and on solid media. Fractions of $\mathrm{L}$ cultures, obtained by differential centrifugation and containing as predominant elements bodies of a diameter $<0.3 \mu$, were also studied. The growth medium served as substrate. The $Q_{\mathrm{O}_{2}}$ values obtained were: unfractionated $\mathrm{L}$ culture, grown in liquid medium, $410 \pm 52$; similar culture, treated for $2 \mathrm{~min}$. in a Mickle apparatus, $<5$; unfractionated L culture, grown on solid medium, $233 \pm 31$; fractionated L elements, $209 \pm 26$. Thus unfractionated $\mathrm{L}$ cultures grown in liquid medium respired about twice as vigorously as $\mathrm{L}$ bodies grown on solid medium. On the other hand, fractions obtained by differential centrifugation respired at about the same speed as did the whole cultures from which they were prepared (the fractionated material was obtained from cultures grown on a solid medium). Mechanical disintegration abolished the respiration of the $\mathbf{L}$ bodies almost completely. The same result was obtained when $\mathrm{L}$ bodies were ruptured by suspending them in distilled water. No oxygen consumption was observed when $\mathrm{L}$ bodies were suspended in Krebs-Ringer 
solution containing glucose (see Mandel, Terranova, Sensenbrenner \& Feo, 1959). No certain relationship was detected between the chemical constitution of fractionated $\mathrm{L}$ cultures and their respiratory activity. In Fig. 2 the circles in the diagram indicate the DNA-content of several batches of fractionated material and the corresponding $Q_{\mathrm{O}_{2}}$ values.

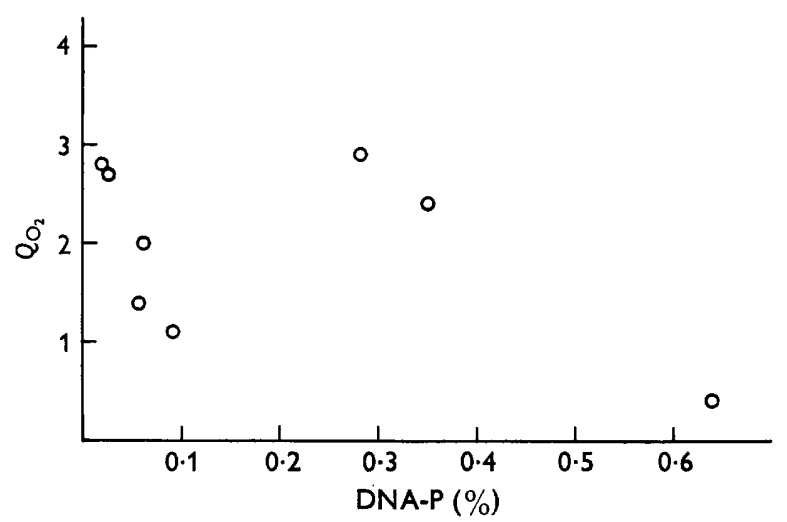

Fig. 2. $Q_{O_{2}}$ values and DNA-P content of fractionated $L$ cultures, predominantly consisting of spherical bodies of a diameter smaller than $0 \cdot 3 \mu$. The fractionation was carried out by means of differential centrifugation.

Estimations of the number of viable elements in unfractionated and fractionated $L$ cultures. These estimations to be described in detail elsewhere were made by the pour-plate method. The nature of the growth medium used was of decisive importance for the outcome of the experiments. Thus in the case of unfractionated L cultures, no growth was obtained in pour plates when fresh Abram's medium was used for diluting the cultures and for pouring the final dilutions. However, a growth medium which gave viable counts not very much lower than the corresponding total counts as determined according to Weibull (1960), was obtained by centrifuging an overnight culture of Proteus L9 and sterilizing the supernatant fluid by heating at $56^{\circ}$ for $1 \mathrm{hr}$. The inclusion of $10 \%(\mathrm{v} / \mathrm{v})$ horse serum in this heated supernatant fluid further slightly increased the viable counts.

When fractionated $\mathbf{L}$ cultures, containing as predominant constituents bodies of diameter $<0.3 \mu$, were tested for viable counts on the serum-containing medium described above, at the most $5 \times 10^{5}$ colonies were obtained per mg. dry wt. fractionated material. It can be calculated that this material must have contained more than $10^{11}$ individual $\mathrm{L}$ bodies (diameter $<0 \cdot 3 \mu$ ). This implies that the number of non-viable bodies would exceed that of the viable ones by a factor greater than $10^{5}$. When fractionated $\mathrm{L}$ cultures were investigated the viable counts obtained could thus be attributed to large $\mathrm{L}$ elements, present as contaminants. Because of their scarcity such elements might easily be overlooked in microscopic preparations.

\section{The biosynthetic activity of small $L$ bodies}

The experiments described in the preceding section showed that of the small $\mathbf{L}$ bodies (diameter $<0 \cdot 3 \mu$ ) isolated by differential centrifugation, at the most very few $(<0.001 \%$ ) were able to grow, divide and finally to form visible colonies under 
the experimental conditions used. It might be argued, however, that these bodies might exhibit less extensive biosynthetic activity. To test for this, small L elements were incubated in a growth medium for $2-4 \mathrm{hr}$. at $30^{\circ}$. At the beginning of the experiment, ${ }^{32} \mathrm{P}$ was added to the incubation mixture at a final concentration of about $15 \mu \mathrm{C} / \mathrm{ml}$. Samples were taken during the incubation and fractionated according to the Schneider procedure. The incorporation of ${ }^{32} \mathrm{P}$ in the nucleic acid fraction of the $\mathrm{L}$ elements during the incubation was followed by radiochemical analyses. The net changes in the content of lipid-P, RNA-P, DNA-P and protein-N of the $\mathrm{L}$ elements were followed by conventional chemical analyses (Schneider, 1945; Burton, 1956).

Three experiments of this kind were performed with different growth media. In the first experiment (indicated by the Roman numeral I in Fig. 4) fresh Abrams's medium (modified as described in the next paragraph) was used, supplemented by about half its volume of a batch of Abrams's medium which had been previously used for growing $\mathbf{L}$ bodies and then centrifuged and sterilized (this medium will subsequently be called 'old' Abrams's medium). In the second experiment (II)

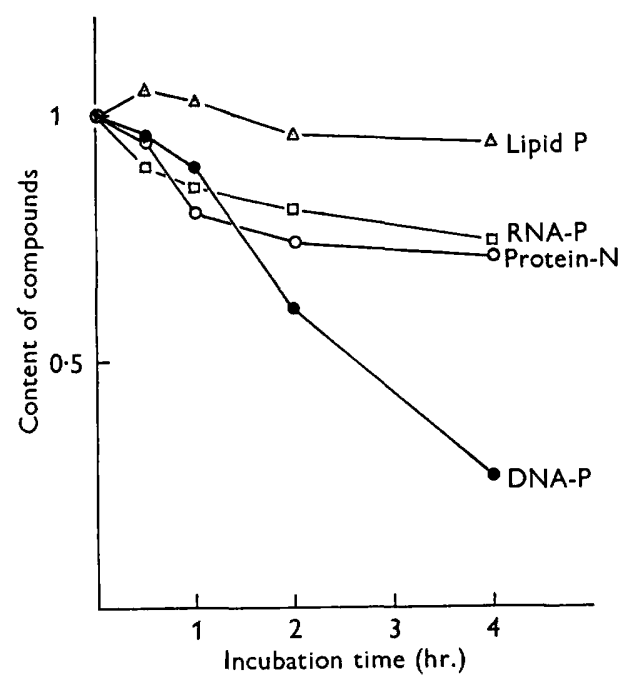

Fig. 3

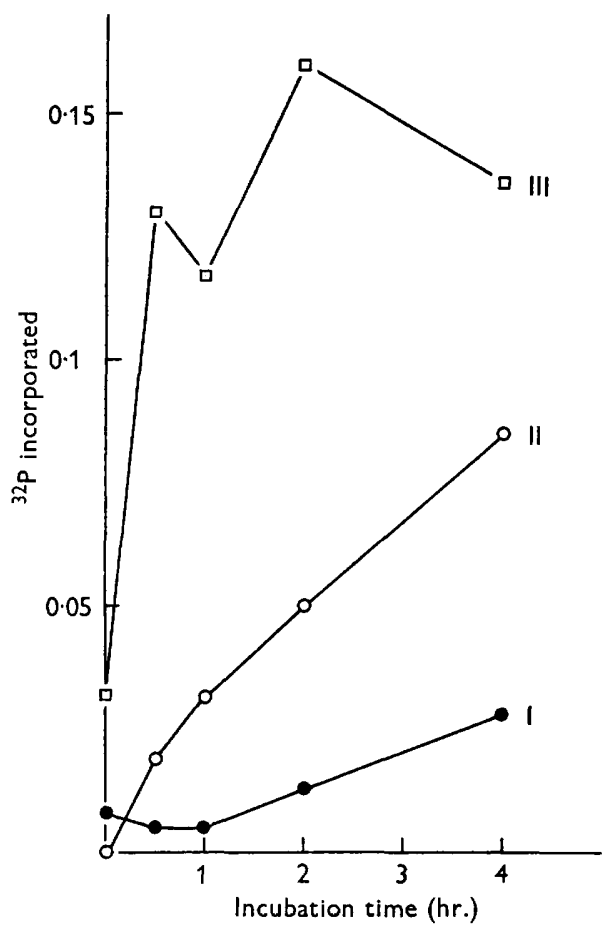

Fig. 4

Fig. 3. Content of lipid-P, protein-N, RNA-P and DNA-P in a fractionated $L$ culture incubated in Abrams's medium supplemented with serum. The content of each compound in the $L$ culture at the beginning of the experiment is given as being equal to unity.

Fig. 4. Incorporation of ${ }^{32} \mathrm{P}$ in fractionated $\mathrm{L}$ cultures, containing as predominant elements spherical bodies of diameter $<0 \cdot 3 \mu$. The amount of incorporated ${ }^{32} \mathbf{P}$ is expressed as $\%$ of nucleic acid-P of the whole culture. The results of three independent experiments (I-III) are given. For experimental details see text. 
only 'old' Abrams's medium was used; in the third experiment (III) 'old ' Abrams's medium, $+10 \%(\mathrm{v} / \mathrm{v})$ horse serum inactivated by heating for $30 \mathrm{~min}$. at $56^{\circ}$. Thus media were used which gave high viable counts for unfractionated $\mathrm{L}$ cultures (see the preceding section).

In all three experiments the phosphate content of the medium was reduced to $2 \%$ of the figure given by Abrams (1955) to minimize the amount of added ${ }^{32} \mathrm{P}$. The tonicity of the medium was restored by the addition of $11 \cdot 4 \mathrm{~g} . \mathrm{KCl} / 1$. medium.

In none of the experiments did chemical analysis show any steady net increase in the content of lipid-P, RNA-P, DNA-P or protein-N in the small $\mathrm{L}$ bodies during the incubation $(4 \mathrm{hr}$.). Instead, a decrease in the content of high molecular weight compounds in these bodies was generally noticed. Fig. 3 shows the results of an experiment carried out with serum added to the medium. When a similar experiment was made with an unfractionated $\mathrm{L}$ culture the content of nucleic acid-P and lipid-P in the culture increased 2-3 times.

Before measuring the radioactivity of the nucleic acid-containing extracts of the fractionated L elements, $0.5 \mathrm{ml}$. $10 \mathrm{~N}$-sulphuric acid, $0.5 \mathrm{ml} .10 \%(\mathrm{w} / \mathrm{v})$ ammonium molybdate and $3 \mathrm{ml}$. of a mixture of equal volumes of isobutanol and benzene was added to $2 \mathrm{ml}$. samples of these extracts. The resulting two-phase systems were shaken for $15 \mathrm{sec}$. In this way, any inorganic phosphate originally adsorbed to the $\mathbf{L}$ bodies would be removed from the aqueous extracts (see Lindberg \& Ernster, 1956). At the same time any inorganic phosphate formed by acid hydrolysis of RNA would also be removed from these extracts. The remaining organic phosphate would, however, correspond to all of the DNA-P and about $50 \%$ of the RNA-P of the bacterial material analysed (Loring, 1955).

The results of the radiochemical measurements performed are given in Fig. 4. It can be seen that the ${ }^{32} \mathbf{P}$ incorporated in the $\mathbf{L}$ elements during the incubation corresponded at the most to between 0.1 and $0.2 \%$ of the nucleic acid-P in the L cultures investigated. The possibility cannot be excluded that this small amount of incorporated phosphorus could be attributed to large $\mathrm{L}$ bodies present as contaminants in the fractionated $\mathrm{L}$ cultures (compare the determinations of viable counts for fractionated $\mathrm{L}$ cultures, described in the preceding section).

\section{DISCUSSION}

The present work shows the marked heterogeneity of bacterial L cultures. Our fractionation experiments, carried out by means of filtration or differential centrifugation, showed that various fractions characterized by different morphological, chemical and metabolic properties, could be prepared from the cultures of Proteus L9 studied. Most of the fractions prepared contained spherical bodies of different sizes as predominant elements. In the present work most attention was paid to $\mathrm{L}$ bodies which had a diameter $<\mathbf{0 \cdot 3} \mu$, which we separated from other elements in cultures of Proteus L9 by differential centrifugation. Light microscope and electron microscope observations showed that larger elements were only occasionally found in the fractionated material thus obtained.

In some bacteria at least the main part of the phospholipid is bound to particulate matter, located in the cytoplasmic membrane (cell envelope) of the intact organism (Mitchell \& Moyle, 1951; Marr \& Cota-Robles, 1957; Weibull, 1957). A 
similar distribution seems to characterize the bacterial succinic dehydrogenase (Mitchell \& Moyle, 1956; Storck \& Wachsman, 1957; Weibull, Beckman \& Bergström, 1959). Catalase, on the other hand, generally seems to be a soluble enzyme, probably located within the bacterial cell (Alexander \& Wilson, 1955; Few, Frazer \& Gilby, 1957; Weibull, Beckman \& Bergström, 1959). Most of the RNA of the bacterial cell is also found in the non-peripheral part of the cytoplasm, the cytoplasmic membrane being almost free from this substance (Marr \& Cota-Robles, 1957; Gilby, Few \& McQuillen, 1958; Weibull, Beckman \& Bergström, 1959).

Those of our chemical and enzymic studies which were carried out with mechanically disintegrated $\mathrm{L}$ bodies (see Tables 4 and 5 ) showed that also in Proteus L9 the phospholipid and the succinic dehydrogenase were largely bound to particulate matter and that the major part of the catalase behaved as a soluble enzyme. This was true of unfractionated and fractionated $\mathrm{L}$ cultures. Thus at least in some respects the $\mathbf{L}$ form investigated seems to possess a structural organization similar to that found in several normal bacteria.

The RNA of small $\mathrm{L}$ bodies (diameter $<\mathbf{0 . 3} \mu$ ) was much more readily sedimented than that of unfractionated cultures consisting mainly of bodies of diameter $>1 \mu$ (see Table 4). Judging from the digestion experiment with DNAse (Table 2), the small $\mathrm{L}$ bodies seemed to contain little if any DNA. In other respects, results of the fractionation and disintegration experiments suggest that the structure of the $\mathbf{L}$ bodies was about the same, irrespective of size. Thus the small $\mathbf{L}$ bodies contained about double the amount of lipid-P than did the unfractionated cultures, and about $40 \%$ less RNA-P (Table 1). Furthermore, our enzyme studies showed that the small $\mathrm{L}$ bodies contained more succinic dehydrogenase and less catalase than unfractionated cultures of Proteus L9. Taking into account the greater surface/ volume ratio of the small elements as compared with the larger ones, these facts could be explained at least qualitatively if it were assumed that the $\mathrm{L}$ bodies consisted of a peripheral layer (the cytoplasmic membrane) containing the major part of the phospholipid and succinic dehydrogenase, and a central part containing the RNA and catalase.

The respiratory experiments showed that the small $\mathrm{L}$ bodies respired as vigorously as the unfractionated ones from which they were derived, and that the respiration rate of $\mathrm{L}$ bodies grown on solid medium was about $50 \%$ lower than that of $\mathrm{L}$ bodies grown in liquid medium.

The work thus demonstrates that $\mathbf{L}$ bodies of different sizes differed in their chemical and metabolic properties. This is in agreement with the results of Mandel and co-workers (Mandel, Feo, Sensenbrenner \& Terranova, 1959; Mandel et al. 1959). Our work has shown, however, that even small $\mathrm{L}$ bodies respire under appropriate conditions (cf. Mandel, Terranova, Sensenbrenner \& Feo, 1959).

More fundamental differences between $\mathrm{L}$ bodies of different sizes than those discussed above appear when the biosynthetic activities are compared. The viable counts were very low for fractionated $\mathbf{L}$ cultures which contained as predominant elements small bodies of diameter $<0.3 \mu$, the counts amounting to about $0.001 \%$ of the total number of individual elements in the samples studied. Probably the viable elements in the fractionated material consisted of large $\mathrm{L}$ bodies, undetected in microscopic preparations of this material because of their scarcity.

Judging from the incorporation experiments performed, the synthesis of nucleic 
acids in small $\mathrm{L}$ elements suspended in a growth medium and incubated for $4 \mathrm{hr}$. amounted at most to about $0 \cdot 1-\mathbf{0 \cdot 2} \%$ of the total nucleic acid content of these elements. Under similar conditions the nucleic acid content of unfractionated $\mathrm{L}$ cultures increased 2-3 times. Thus the nucleic acid synthesis in the small $\mathrm{L}$ bodies was more than 1000 times less than in whole $\mathrm{L}$ cultures; however, the role of contaminating $L$ bodies of larger sizes has to be taken into account. It then seems possible that all the nucleic acid synthesis which occurred in the fractionated material might be attributed to such contaminants. The possible occurrence of exchange reactions should also be borne in mind. The biosynthetic activity of the small $\mathrm{L}$ elements seems therefore questionable, as judged from the data presented here. Consequently their role in the life cycle of the $\mathrm{L}$ cultures, as described by Tulasne (1955), seems doubtful. On the other hand, these small bodies seems to possess a certain degree of structural organization, and they can hardly be regarded merely as protoplasmic debris. This is especially evident from the fact that mechanically prepared debris of Proteus L9 showed at most a very low degree of respiratory activity, whereas small $\mathrm{L}$ bodies isolated by differential centrifugation respired about as intensely as unfractionated $\mathbf{L}$ cultures. The chemical and enzymic composition of the small $\mathrm{L}$ bodies also suggests a certain degree of structural organization. Earlier work about the structure of small $\mathrm{L}$ elements as seen by the electron microscope should also be mentioned in this connexion (Thorsson \& Weibull, 1958).

This investigation was part of a programme on the submicroscopic structure of the bacterial cell financially supported by the Swedish Natural Science Research Council.

\section{REFERENCES}

Abrams, R. Y. (1955). A method for the cultivation of $L$ forms in liquid media. J. Bact. 70, 251.

Alexander, M. \& Wilson, P. W. (1955). Enzyme localization in Azotobacter vinelandii. Proc. nat. Acad. Sci., Wash. 41, 843.

Allen, R. J. L. (1940). The estimation of phosphorus. Biochem. J. 34, 858.

Backus, R. C. \& Williams, R. C. (1950). The use of spraying methods and of volatile suspending media in the preparation of specimens for electron microscopy. $J$. appl. Phys. 21, 11.

Bonnichens, R. K., Chance, B. \& Theorell, H. (1947). Catalase activity. Acta chem. scand. $1,685$.

Burton, K. (1956). A study of the conditions and mechanism of the diphenylamine reaction for the colorimetric estimation of deoxyribonucleic acid. Biochem. J. 62, 315.

Dienes, L. \& Weinberger, H. J. (1951). The L forms of bacteria. Bact. Rev. 15, 245.

Few, A. V., Fraser, M. J. \& Girby, A. R. (1957). The intracellular catalase of Micrococcus lysodeikticus. Biochim. biophys. Acta, 24, 306.

Gilby, A. R., Few, A. V. \& McQuillen, K. (1958). The chemical composition of the protoplast membrane of Micrococcus lysodeikticus. Biochim. biophys. Acta, 29, 21.

KANDler, O. \& Kandler, G. (1960). Die L-Phase der Bakterien. Ergebn. Mikrobiol. 33, 97.

Klieneberger-Nobel, E. (1956). Über die Wesensverschiedenheit der peripneumonieähnlichen Organismen und der L-Phase der Bakterien. Zbl. Bakt. (1 Abt.), 167, 345.

KLIENEBERGER-NoBeL, E. (1960). L-forms of bacteria. In The bacteria (ed. I. C. Gunsalus \& R. Y. Stanier), vol. I, p. 443. New York and London: Academic Press Inc.

LiNDBERg, O. \& ERNSTER, L. (1956). Determination of organic phosphorus compounds by phosphate analysis. In Methods of biochemical analysis (ed. D. Glick), vol. III, p. 1. New York and London: Interscience Publishers. 
Loring, H. S. (1955). Hydrolysis of nucleic acids and procedures for the direct estimation of purine and pyrimidine fractions by absorption spectrophotometry. In The Nucleic Acids (ed. E. Chargaff \& J. N. Davidson), vol. I, p. 91. New York: Academic Press Inc.

Mandel, P., Terranova, T. \& Sensenbrenner, M. (1957). Fractionnement des formes L fixées du Proteus P 18. C.R. Acad. Sci., Paris, 245, 1469.

Mandel, P., Feo, F., Sensenbrenner, M. \& Terranova, T. (1959). Étude de quelques activités enzymatiques de divers types morphologiques de formes $L$ stables dérivées $d u$ Proteus P 18. C.R. Acad Sci., Paris, 248, 315.

Mandel, P., Terranoya, T., Sensenbrenner, M. \& Feo, F. (1959). Oxygen consumption of different forms of stable L Proteus $\mathbf{P} 18$ growing in hypertonic liquid medium. Nature, Lond. 183, 194.

Mandel, P., Sensenbrenner, M., Terranova, T., Gregario, G. \& Bader, A. M. (1959). Distribution of nucleic acids among different stable $\mathrm{L}$ forms of Proteus P. 18. Nature, Lond. 184, 566.

MARR, A. G. (1960). Localization of enzymes in bacteria. In The Bacteria (ed. I. C. Gunsalus \& R. Y. Stanier), vol. I, p. 443. New York and London: Academic Press Inc.

MARR, A. G. \& Cota-Robles, E. H. (1957). Sonic disruption of Azotobacter vinelandii. J. Bact. 74, 79.

Mrckle, H. (1948). Tissue disintegrator. J. R. Micr. Soc. 68, 10.

Mitchell, P. \& Moyle. J. (1951). The glycerophospho-protein complex envelope of Micrococcus pyogenes. J. gen. Microbiol. 5, 981.

Mrtchell, P. \& Moyle, J. (1956). The cytochrome system in the plasma membrane of Staphylococcus aureus. Biochem. J. 64, 19 P.

Schneider, W. C. (1945). Phosphorus compounds in animal tissues. I. Extraction and estimation of desoxypentose nucleic acid and of pentosenucleic acid. J. biol. Chem. 161, 293.

Storck, R. \& WaChSman, J. (1957). Enzyme localization in Bacillus megaterium. J. Bact. 73, 784 .

Taubeneck, U. (1956). Die Penicillininaktivierung durch Proteus-Arten. Zbl. Bakt. (1. Abt.), 167, 345.

Thorsson, K. G. \& Weibule, C. (1958). Studies on the structure of bacterial L forms, protoplasts and protoplast-like bodies. $J$. Ultrastructure Res. 1, 412.

Tulasne, R. (1955). Bilan de nos connaissances sur les cycles bactériens du type $\mathrm{L}$ et sur les formes $L$ des bactéries. Biol. méd., Paris, 44, 391.

Weibull, C. (1957). The lipids of a lysozyme sensitive Bacillus species (Bacillus ' $M$ '). Acta chem. scand. 11, 881.

WeIBULL, C. (1960). Counting procedure for phase contrast microscopy. J. Bact. 79, 155.

Weibull, C. \& Beckman, H. (1960). Growth of bacterial L forms and bacterial protoplasts. J. Bact. 79, 638.

Weibuld, C., Beckman, H. \& Bergström, L. (1959). Localization of enzymes in Bacillus megaterium, strain M. J. gen. Microbiol. 20, 519. 